\title{
Bioluminescence mechanism on new systems
}

\author{
Minoru Isobe,* Hiroyuki Takahashi, Ken Usami, Masahiko Hattori and Yoshiko Nishigohri \\ Laboratory of Organic Chemistry, School of Agriculture, Nagoya University \\ Chikusa, Nagoya 464-01, Japan
}

\begin{abstract}
New bioluminescence systems in luminous organisms such as mushrooms, a snail, a squid etc. were investigated. The chromophores emitting light were determined. The mushroom, Lampteromyces japonicus, involves a flavin derivative as the light emitting species. Three components were necessary in the chemiluminescence of the homogenate of this mushroom; one of the smallest constituents being L-tyrosine. The chromophore in the luminous squid, Symplectoteuthis oualaniensis, was identified to be dehydrocoelenterazine. This chromophore exists as conjugate adduct in the photoprotein. One of the old luminescence systems, a firefly, was applied to detect protein phosphatases. This is an example to request developments on the new bioluminescence system.
\end{abstract}

We have been searching for new bioluminescent system in living organisms as animals, fungi, etc. Occurrence of many bioluminescent organisms observed in Japan as well as in tropical area has stimulated chemical studies, which have been progressing in academic interests as well as commercial fields to apply to biomedical analysis because of sensitive and selective nature of light. An example is fungi (including mushroom) luminescence, which is found in Thailand, Malaysia and/or Singapore, such as Pleurotus lampas, $P$. lunaillustria, Omphalia flavida, Mycena manipularis, $M$. pruinoso-viscida, $M$. chlorophos, $M$. noctileucens. Moon night mushroom, Lampteromyces japonicus, is a large luminous mushroom found in Japan. The light emitter in this mushroom, named lampteroflavin, has the structure 1, but the luminescent mechanism is unsolved until finding of luciferin equivalent, that is going to the excited state. ${ }^{1}$ Recently, we have found that L-tyrosine as a small molecular weight fraction exhibited the luminescence when mixed with a high molecular and medium molecular weight fractions in the presence of $\mathrm{Fe}(\mathrm{II})$ and hydrogen peroxide. The continuation of the efforts will provide us new features of basic principles going on in the biological system as well as analytical application. Application of the new luminescent system will further follow the elucidation of mechanism.

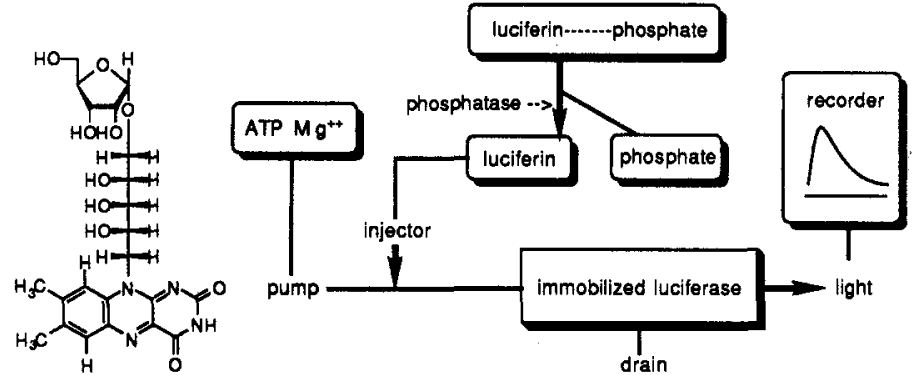

lampteroflavin (1)
Fig. 1

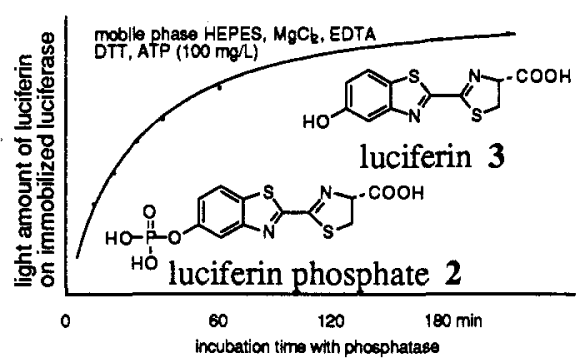

Fig. 2 
We chemically synthesized luciferin phosphate $(2)^{2}$ and used as substrate for various phosphatases, such as alkali, acid and protein phosphatases to liberate free luciferin (3). This luminescence system was extended to detect inhibitory activity of protein phosphatases caused by okadaic acid. ${ }^{3}$ Our interests started to combine the synthetic activity of this inhibitor okadaic acid ${ }^{4}$ and tautomycin ${ }^{5}$ with the studies to uncover the mechanism of this inhibition. As shown in Fig. 1, the luminescence detector is similar to liquid chromatograph equipped with pump (sending buffer containing ATP and $\mathrm{Mg}^{++}$), injector (sampler or autosampler), immobilized luciferase (packed in a transparent tubing and placed in front of photo multiplier) and data processor. The hydrolysate mixture of the phosphatase and luciferin phosphate (2) was directly injected to this detector. Fig. 1 also illustrates the principle for monitoring the generated luciferin as a results of phosphatases. The detected light was plotted against time of incubation, amount of phosphatases, etc. Now the amount of detected light is set to be constant at an amount of luciferin $(0.1 \sim 500 \mathrm{pmol})$, incubation time $(10 \sim 30 \mathrm{~min})$ at $25^{\circ} \mathrm{C}$, for example. To this steady state condition, was added okadaic acid (5) in the range of $10^{-14} \sim 10^{-12} \mathrm{~mol}$, as is indicated in Fig. 2. By using this luminescence system, the inhibition of okadaic acid (5) to protein phosphatase was, in fact, measured with type $2 \mathrm{~A}$, which was kindly provided by Professor Takai. Scheme 1 illustrates the principal use of luciferin phosphate to detect luciferin. ${ }^{6}$

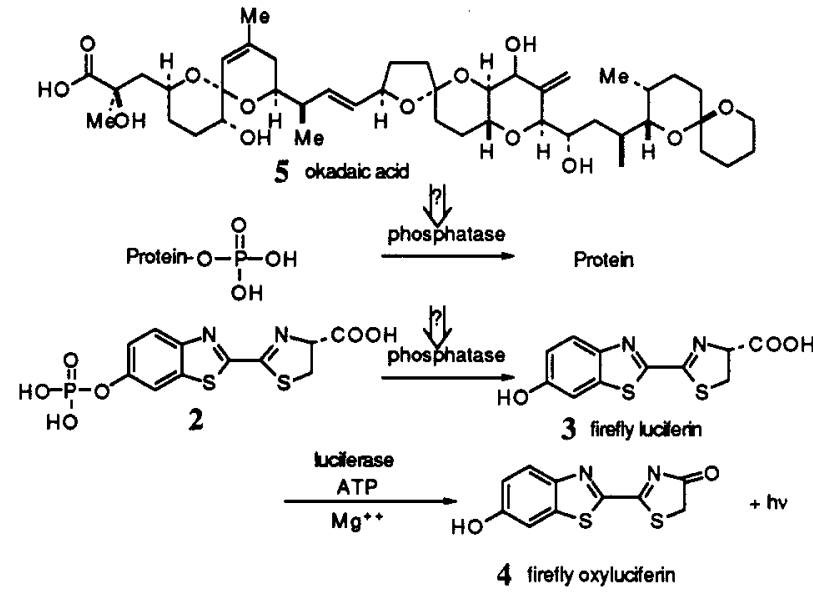

Scheme 1

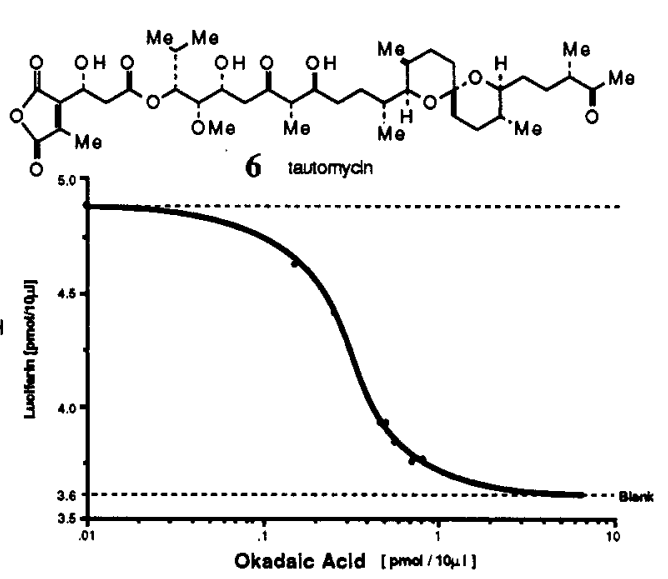

Fig. 3

The inhibition experiment shown in Fig. 3 was carried out with 0.27 pmol of protein phosphatase type $2 \mathrm{~A}$ and incubated with luciferin phosphate (ca. $100 \mathrm{pmol}$ ) for $50 \mathrm{~min}$ at $\mathrm{pH} 7.75$. Initial luminescence produced by the phosphatase without okadaic acid was about 4.85 pmol, while less than 1 pmol of okadaic acid inhibited most of its activity to leave ca. $3.6 \mathrm{pmol}$ that is considered to be the blank. This inhibition is counted to occur between each single molecule of inhibitor and phosphatase. Application of this method to tautomycin (6) was recently confirmed to work at the same level.

Bioluminescence of marine organisms is widely recognized phenomenon, and the chemistry of the chromophore (luciferin) of squids has been studied only on Watasenia scintillans, $\mathrm{B}^{7}$. Many of these luminescent systems involve a common chromophore, coelenterazine (7), which is known in other marine luminescent system, e.g.. Oplophorus ${ }^{8}$ Watasenia (as preluciferin ${ }^{9}$ ), Aequoria victoria. ${ }^{10}$ We have recently studied the chromophore involved in a different luminous squid, Symplectoteuthis oualaniensis L (Japanese name, Tobi-Ika). ${ }^{11}$ The yellow luminous organs are located on the back-forward of mantle in ovarian range $(5 \mathrm{~cm} \times 3 \mathrm{~cm})$. In 1981, Tsuji et al. reported biochemical aspects of luminescence of $S$. oualaniensis; thus, 
sodium or potassium ions being necessary for the luminescence. ${ }^{12}$ We have recently concluded that the chromophore of $S$. oualaniensis is dehydrocoelenterazine $(8)^{13}$ and that it exists as the conjugate addition product as 9.

The luminescence spectrum of $S$. oualaniensis shows the maximum at $470 \mathrm{~nm}$, that suggests the corresponding oxyluciferin should show blue fluorescence. ${ }^{14}$ The luminous organs $(17 \mathrm{~g})$ were separated at ca. $0^{\circ} \mathrm{C}$ from 30 bodies of $S$. oualaniensis. The organs were freeze-dried $(5.8 \mathrm{~g})$ and then homogenized at $-78^{\circ} \mathrm{C}$ in acetone solvent $(100 \mathrm{~mL})$ under nitrogen atmosphere. The mixture was filtered through Büchner funnel and the residue was washed with cold acetone $(50 \mathrm{~mL})$ to give pale yellowish powder $(5 \mathrm{~g})$. No fluorescent compound was found in acetone extracts. This acetone-powder showed bioluminescence activity when mixed with $\mathrm{KCl}$ solution and also showed chemiluminescence activity when suspended in aprotic polar solvent such as DMSO, DMF 15 in the presence of molecular oxygen.

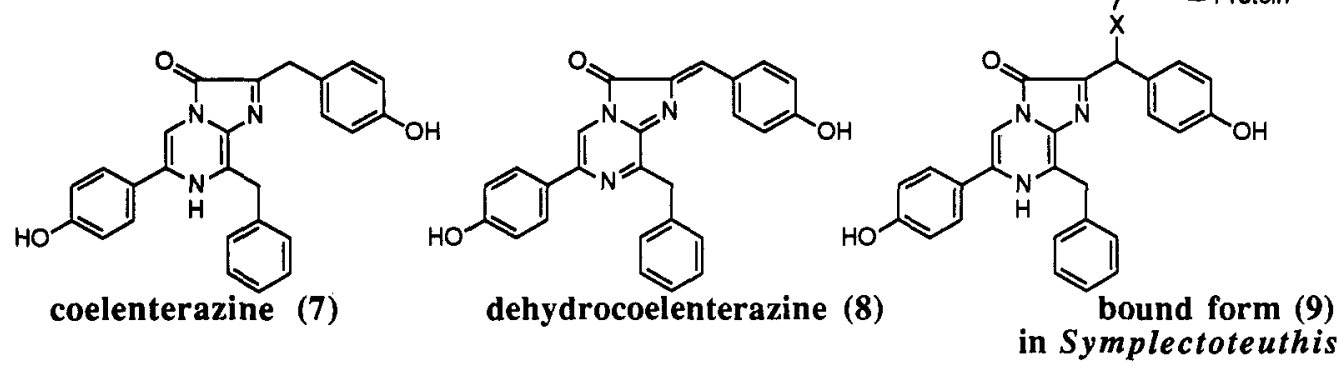

After mixing with $1 M \mathrm{KCl}$ to observe light, the acetone-powder was extracted with a mixture of $\mathrm{MeOH}$ and acetone (1:1) to give a fraction having blue fluorescence. This compound was separated by Sephadex LH-20 and then by $\mathrm{SiO}_{2}$ chromatography to isolate a blue fluorescent compound which was identified to be coelenteramine (4) [ ${ }^{1} \mathrm{H}$ NMR $\left(\mathrm{CD}_{3} \mathrm{OD}, 500 \mathrm{MHz}\right) \delta 4.15(2 \mathrm{H}, \mathrm{s}), 6.86(2 \mathrm{H}, \mathrm{d}, J=10 \mathrm{~Hz}), 7.23(1 \mathrm{H}, \mathrm{m})$, 7.30(4H, AB), 7.73(2H, d, $J=10), 8.22(1 \mathrm{H}, \mathrm{s}) \mathrm{ppm}$; FAB-MS m/z $278(\mathrm{M}+1)$; Fluorescence $E m_{\max } 439$ $\mathrm{nm}(E x 356 \mathrm{~nm})]$ by comparison of chromatographic and spectroscopic data with chemically synthesized authentic sample (4). ${ }^{16}$ It implies that extraction of the acetone-powder gave 4 but not oxyluciferin equivalent to 5 even after addition of $1 M \mathrm{KCl}$ to the homogenate of the photogenic organs. ${ }^{17}$ These negative experiments prompted us to extract anything retaining luminescent activity, that can be measured by chemiluminescence detection.

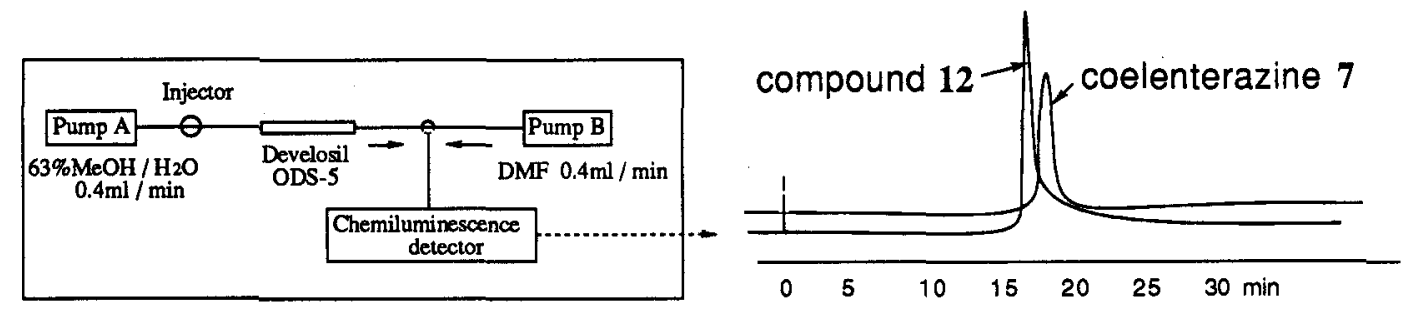

Fig. 4 Chemiluminescence detection and chromatogram of luminous compounds 1 and 6

The acetone-powder of the photogenic organs of $S$. oualaniensis was extracted with $\mathrm{MeOH}$, and the extract was separated by Sephadex LH-20 column chromatography. Two fractions showing fluorescence were separated. The first fraction was analyzed by TLC (silica gel, EtOAc) and HPLC on ODS column equipped with chemiluminescence detector as shown in Fig. 4. The results suggests the structures to be coelenterazine (7) in very trace amount (only detectable by chemiluminescence $<10^{-10}$, but not detectable by UV monitor). The second fraction, that eluted slowly with interaction with Sephadex LH-20 gels, was 
identified to be dehydrocoelenterazine (8). The dehydro body (8) is characteristic deep-red color and does not show luminescence activity. This compound (8) was also found in the following $\mathrm{MeOH}$-acetone extracts (having luminescence activity) in smaller amount. But dehydrocoelenterazine (8) became non-detectable from the acetone-powder after treatment with $1 M \mathrm{KCl}$ and observe luminescence.

The acetone-powder $(5 \mathrm{~g})$ was suspended in a mixture of $\mathrm{MeOH}$ and acetone $(1: 1,100 \mathrm{~mL})$ at room temperature for $10 \mathrm{~min}$ and then filtered through Büchner funnel. The residue repeatedly extracted once more with $\mathrm{MeOH}$-acetone $(1: 1,50 \mathrm{~mL})$ and three times with $\mathrm{MeOH}(50 \mathrm{~mL})$. The extracts were combined and concentrated into $20 \mathrm{~mL}$ and the residue was allowed to stand for $1 \mathrm{hr}$ at $0^{\circ} \mathrm{C}$ to form precipitates. After filtering the precipitate, the filtrate was separated by a Sephadex LH-20 column ( $24 \mathrm{~mm} \times 425 \mathrm{~mm}$ ) using $\mathrm{MeOH}$ as eluant to collect yellow fraction showing chemiluminescence activity (with DMF, vide supra). The fraction was concentrated to dryness and dissolved in aliquot of $10 \% \mathrm{H}_{2} \mathrm{O}-\mathrm{MeOH}$. Filtering the precipitate, the luminescence fraction was applied onto an ODS column (Develosil ODS-10) with $90 \% \mathrm{MeOH}$ as eluant to collect fractions having chemiluminescence activity, which was checked after fractionation by the method using ODS column and 63\% $\mathrm{MeOH}$ as shown in Fig. 4. The active fractions were collected and repeatedly separated with the same column with $65 \% \mathrm{MeOH}$ (once) and then $60 \% \mathrm{MeOH}$ (once) to yield a chemiluminescence fraction having different retention time of the luminescence peak from coelenterazine (2)(see Fig. 4). This luminous compound was assigned to have structure $6 ;{ }^{1} \mathrm{H}$ NMR $\left(\mathrm{CD}_{3} \mathrm{OD}, 500 \mathrm{MHz}\right) \delta$ $2.16(3 \mathrm{H}, \mathrm{s}), 3.14(1 \mathrm{H}, \mathrm{dd}, J=17,5.5 \mathrm{~Hz}), 3.74(1 \mathrm{H}, \mathrm{dd}, J=17,10), 4.43(2 \mathrm{H}, J=14), 4.75(1 \mathrm{H}, \mathrm{dd}, J=$ $10,5.5), 6.70(2 \mathrm{H}, \mathrm{d}, J=9.0), 6.88(2 \mathrm{H}, \mathrm{d}, J=9.0), 7.20(2 \mathrm{H}, \mathrm{d}, J=9.0), 7.25(1 \mathrm{H}, J=7.3), 7.32(2 \mathrm{H}, \mathrm{d}$, $J=7.3), 7.43(2 \mathrm{H}, \mathrm{d}, J=7.6), 7.4(1 \mathrm{H}, \mathrm{b}) \mathrm{ppm} ; \mathrm{FAB}-\mathrm{MS} \mathrm{m} / \mathrm{z} 480(\mathrm{M}+1)$; UV (MeOH) $\lambda_{\max } 261,435 \mathrm{~nm}$; Fluorescence $\left.E m_{\max } 537 \mathrm{~nm}(E x 429 \mathrm{~nm})\right]$.<smiles>Nc1ncc(-c2ccc(O)cc2)nc1Cc1ccccc1</smiles>

coelenteramine (10)
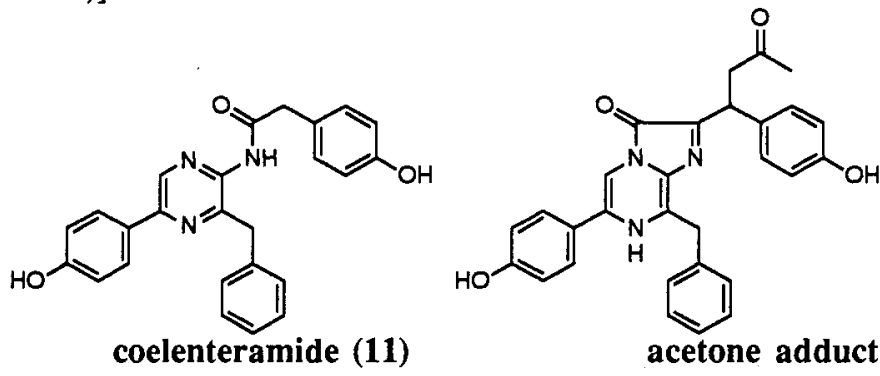

acetone adduct (12)

The structure 6 being adduct of solvent acetone to dehydrocoelenterazine (2) was confirmed by synthesis; thus, a solution of $2(2.5 \mathrm{mg})$ dissolved in $\mathrm{MeOH}$-acetone $(1: 1,0.3 \mathrm{~mL})$ containing benzylamine $(4 \mathrm{mg})$ was stirred at $\mathrm{rt}$ for $30 \mathrm{~min}$ and the mixture was directly separated by Sephadex LH-20 and then ODS-10 (vide supra) to afforded 6 ( $0.3 \mathrm{mg}$, all spectra being identical with the sample as above) in ca. $15 \%$ yield. Alternatively, synthetic dehydrocoelenterazine $(2,8.0 \mathrm{mg})$ was suspended with the residue of $\mathrm{MeOH}$-acetone extraction of the acetone-powder $(150 \mathrm{mg})$ in a mixture of $\mathrm{MeOH}$-acetone $(1: 1,25 \mathrm{~mL})$ with stirring overnight at room temperature. TLC $\left(\mathrm{SiO}_{2}\right)$ analysis showed presence of an unstable intermediate, which can be assigned to be the enamine (6a). The mixture was filtered and the filtrate was concentrated to give residue, which was purified with a Sephadex LH-20 column and then with an ODS-10 column to yield $3.1 \mathrm{mg}$ of 6 . This adduct (6), when further treated with $\mathrm{NaOH}$ in DMF solvent with bubbling oxygen, yielded the oxyluciferin-type compound 7 (FAB-MS m/z= 468, M+1)(see Scheme 1). 


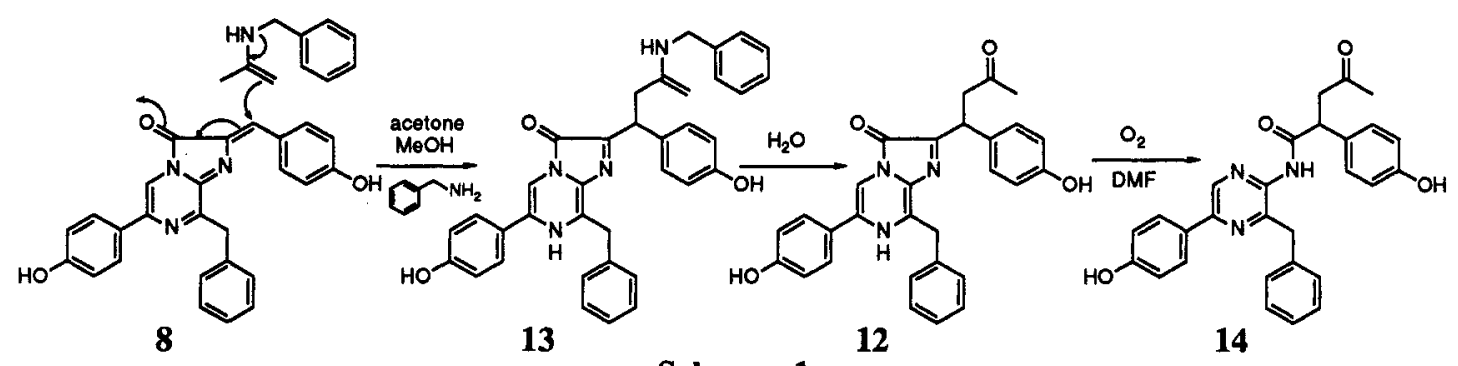

Scheme 1

Dithiothreitol (DTT, $8.8 \mathrm{mg}$ ) was added to $2(2.4 \mathrm{mg})$ in a mixture of $\mathrm{MeOH}$-acetone $(1: 1,0.3 \mathrm{~mL})$, and product was attempted to separate. But it decomposed in a column to yield dehydrocoelenterazine (2). The S-adduct existed only as constituents of equilibrium, since FAB-MS of this mixture (in the presence of DTT) gave $m / z 576$ equivalent to $M+1$ of compound 8 .

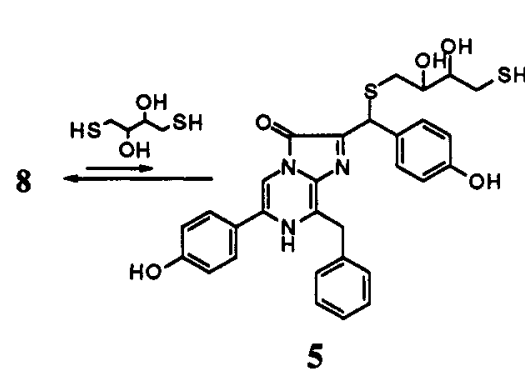

Scheme 3

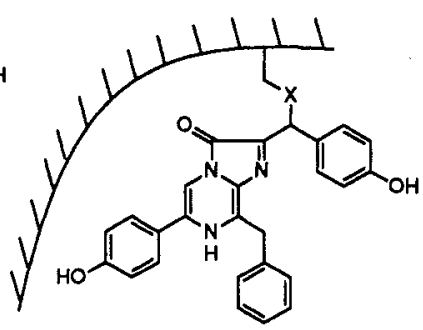

16

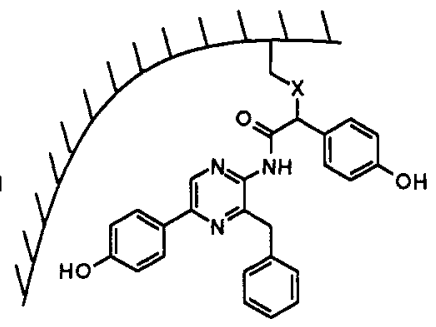

17

Fig. 5 Suggested form of chromophore in photoprotein of aequorin and $S$. oualaniensis

Dehydorocoelenterazine-acetone adduct (6) having luminescence ability was extracted from the luminous organs. This is an artifact, addition of solvent to dehydrocoelenterazine (2), judging from the fact that similar extraction with a mixture of methyl ethyl ketone and $\mathrm{MeOH}$ afforded mixture of adducts of the ketone.

When the homogenate was extracted only with $\mathrm{MeOH}$ (without acetone), dehydrocoelenterazine (2) was extracted, its amount being estimated about 20\% from the total luminescent light. None of 2 nor $\mathbf{6}$ was, however, detected after luminescence $(470 \mathrm{~nm})$ of the homogenate of the photogenic organs by addition of $\mathrm{KCl}$, indicating that the bioluminescence of $S$. oualaniensis consumed dehydrocoelenterazine 2 . Although dehydrocoelenterazine (2) itself does not exhibit any luminescence activity, some derivatives produced by addition (such as 6,8 etc.) should retain the activity. The dithiothreitol adduct to dehydrocoelenterazine, although existing only as equilibrium, in agreement with higher and longer luminescence activity of this squid as reported by Tsuji et al. Dehydrocoelenterazine absorbs long wavelength light ( $450 \mathrm{~nm}$ ?) to become reddish color, but the photogenic organ is not red but yellow-brown (identical with the acetone adduct 6 ), indicating that the existing conjugate system is broken. This phenomenon is interpreted by deconjugative addition of nucleophile in protein (e.g. a functional residue on lysine, cysteine etc.). These facts led us to conclude that dehydrocoelenterazine 2 exists as adduct as 3 .

In the squid luminescence in $S$. oualaniensis, the system requires molecular oxygen and monovalent cations (e.g. $\mathrm{Na}^{+}, \mathrm{K}^{+}$, etc.) for bioluminescence. We found that only a high molecular fraction (from gel filtration chromatography with Bio-gel P-6) emits light $(470 \mathrm{~nm})$ by addition of $\mathrm{KCl}$ and $\mathrm{O}_{2}$. These facts suggest a new type of binding with dehydrocoelenterazine-acetone adduct. 


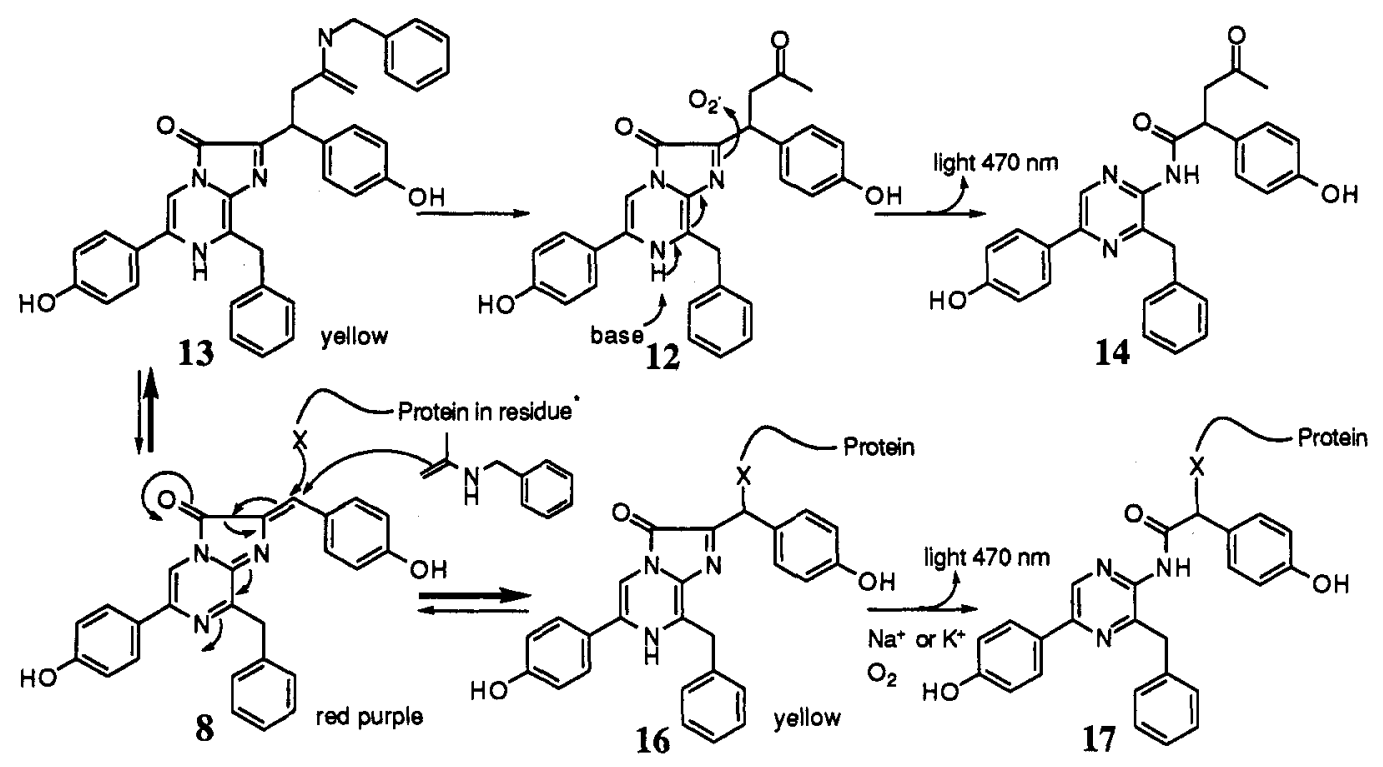

Scheme 4

In conclusion, the possibility of the dehydrocoelenterazine adduct as the luciferin of $S$. oualaniensis bioluminescence system becomes apparent through the current studies.

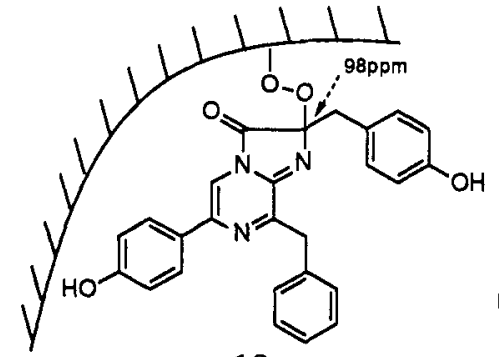

18<smiles>O=C1C2=NC(Cc3ccc(O)cc3)=NC(O)C(c3ccc(O)cc3)=NC1=C2Cc1ccccc1</smiles>

19

jelly fish (A. victoria) aequorin, ${ }^{20}$ 5-coelenterazinol (reduction product) ${ }^{21}$

Aequorin, an well-known photoprotein, found in jelly fish Aequoria victoria, induces bioluminescence by addition of cations such as $\mathrm{Ca}^{++}$and no other component is necessary for this luminescence system. ${ }^{18}$ This system involves coelenterazine as chromophore, that tightly binds with protein. Thus, apoprotein of aequorin binds with coelenterazine (1) luminescent chromophore prior to receive $\mathrm{Ca}^{++}$. Shimomura et al . suggested the binding of coelenterazine to apoaequorin being through peroxide linkage as $18 .{ }^{19}$ In fact, no molecular oxygen is required for luminescence of this complex. Kishi et al. verified this linkage by means of NMR (the C-2 being at $\delta 98 \mathrm{ppm}, 18$ ) to suggest its reduction product (yellow compound) to have 2-hydroxy group. ${ }^{20}$ We have revised the yellow compound to have hydroxy group at the 5-position (10). ${ }^{21}$ Cormier et al. suggested another mechanism without such peroxide linkage. 22 


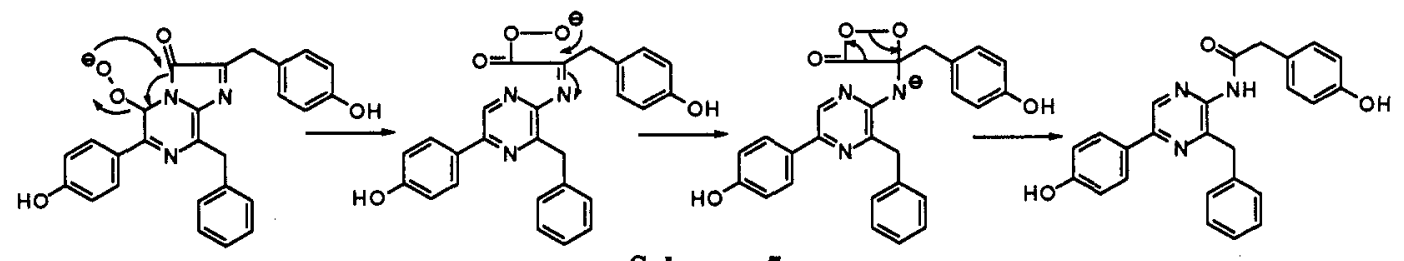

Scheme 5

The mechanisms shown in Scheme 4 and 5 are hypothesis connected to the finding of 5-coelenterazinol (19), a reduction product. Our approach involves photo oxidation at low temperatures to contribute uncovering such reaction process including the peroxide intermediate. To persuade these studies, we have synthesized several coelenterazine analogs having ${ }^{13} \mathrm{C}$ at position 2 and/or 5 , and analyzed the $\mathrm{nmr}$ spectra. These approach will lead us to conclude the direct proof of the luminescence mechanism.

Acknowledgments The authors are indebted to Grant-in-Aid for Special Topics from the Ministry of Education, Science and Culture of Japan and to Taiko Foundation (Nagoya) for financial supports to this research.

\section{References and Notes}

1. Uyakul, D.; Isobe, M.; Goto, T. Bioorganic Chemistry, 1989, 17, 454: Tetrahedron, 1990, 46, 1367. Isobe, M.; Takahashi, H.; Goto, T. Tetrahedron Letters, 1990, 31, 717., Takahashi, H.; Isobe, M.; Goto, T. Tetrahedron, 1991, 47, 6215.

2. Toya, Y.; Takagi, M.; Nakata, H.; Suzuki, N.; Isobe, M.; Goto, T. Bull. Chem. Soc. Jpn., 1992, 65, 392. Toya, Y.; Takagi, M.; Nakata, H.; Kondo, T.; Isobe, M.; Goto, T. Bull of Chem. Soc. Japan., 1992, 65, 2604.

3. Takai, A.; Bialojan, C.; Troschika, M.; Ruegg, J. C. FEBS Lett., 1987, 217, 81. Nishiwaki, S.; Fujiki, H.; Suganuma, M.; Furuya-Suguri, F.; Matsushima, R.; Iida, Y.; Ojika, M.; Yamda, K.; Uemura, D.; Yasumoto, T.; Schmitz F. J.; Suginuma, T. Carcinogenesis 1990, 11, 1837. Yatsunami, J.; Fujiki, H.; Suganuma, M.; Nishiwaki, S.; Ojika, M.; Yamada, K.; Levine, L. Toxicon, 1991, 29, 1409. Takai, A.; Murata, M.; Torigoe, K.; Isobe, M.; Mieskes, G.; Yasumto, T.; Biochem. J. 1992, 284, 539. Hokama, Y.; Hong, T. W. P.; Isobe, M.; Ichikawa, Y.; Yasumoto, T. J. Clin. Lab. Anal., $1992,6,54$.

4. Isobe, M.; Ichikawa, Y.; Goto, T. Tetrahedron Letters, 1086, 27, 963. Isobe, M.; Ichikawa, Y.; Bai, D-L.; Masaki, Y.; Goto, T. Tetrahedron, 1987, 43, 4767.

5. Cheng,X.,-C.; Kihara, T.; Kusabake, H.; Magae, J.; Kobayashi, Y.; Fang, R. -P.; Ni, Z. F.; Shen, Y.C.; Ko, K.; Yamaguchi, I.; Isono, K. J. Antibiot., 40, 907 (1987). Ubukata, M.; Cheng, X.-C.; Isono, K. J. Chem. Soc. Chem. Comm., 244 (1980): J. Antibiot., 43, 809 (1990). Ubukata, M.; Cheng, X.-C.; Isobe, M.; Isono, K.J. Chem. Soc. Perkin Trans. 1, 617-624 (1993).

6. Hattori, M.; Yokoe, C.; Isobe, M.; Goto, T.; Takai, A. to be published.

7. Inoue, S.; Kakoi, H.; Goto, T. Tetrahedron Lett. 1976, 28, 2971.

8. Hori, K.; Wampler, J. E.; Matthews, J. C.; Cormier, M. J. Biochemistry 1973, 12, 4463.?

9. Inoue, S.; Sugiura, S.; Kakoi, H.; Hashizume, K.; Goto, T.; Iio, H. Chemistry Lett. 1975, 141.

10. Shimomura, O.; Johnson, F. H. Nature 1975, 256, 236.

11. Young, R. E. Comp. Biochem. Physiol. 1975, 52B, 141.

12. Tsuij, F. I.; Leisman, G. Proc. Natl. Acad. Sci. USA 1981, 78, 6719. 
13. Inoue, S.; Taniguchi, H.; Murata, M.; Kakoi, H.; Goto, T. Chemistry Lett. 1977, 259.

14. Goto, T.; Iio, H.; Inoue, S.; Kakoi, H. Tetrahedron Lett. 1974, 26, 2321.

15. a) Goto, T. Pure Appl. Chem. 1968, 17, 421. b) Goto, T.; Inoue, S.; Sugiura, S. Tetrahedron Lett. 1968, 3873. c) Inoue, S.; Okada, K.; Tanino, H.; Kakoi, H. Chemistry Lett. 1987, 417.

16. Kishi, Y.; Tanino, H.; Goto, T. Tetrahedron Lett. 1972, 27, 2747.

17. To check any enzymatic digestion, an given amount of coelenteramide (synthetic) was added to the homogenate and recovered to find no change after the same extraction condition.

18. Shimomura, O.; Johnson, F. H.; Saiga, Y. J. Cell. Comp. Physiol. 1962, 59, 223.

19. Johnson, F. H.; Shimomura, O. Methods in Enzymol. 1978, 57, 271.

20. Musicki, B.; Kishi, Y.; Shimomura, O. J. Chem. Soc., Chem. Commun. 1986, 1566.

21. Teranishi, K.; Isobe, M.; Yamada, T.; Goto, T. Tetrahedron Lett. 1992, 33, 1303.

22. Ward, W. W.; Cormier, M. J. Proc. Natl. Acad. Sci. USA 1975, 72, 2530. 